\title{
Changes in the activity of adult stages of Dermacentor reticulatus (Ixodida: Amblyommidae) induced by weather factors in eastern Poland
}

\author{
Alicja Buczek*, Katarzyna Bartosik and Zbigniew Zając
}

\begin{abstract}
Background: The host-seeking activity in Dermacentor reticulatus ticks undergoes rhythmical changes correlated with environmental conditions. Therefore, this study is focused on investigating the activity of adult stages of the species during weather changes occurring in winter months in eastern Poland, i.e. a period of tick diapause.

Methods: D. reticulatus ticks were collected in a meadow ecosystem near Lublin (eastern Poland, $51^{\circ} 36^{\prime} \mathrm{N}, 22^{\circ} 58^{\prime} \mathrm{E}$ ) between the third decade of November 2011 and the third decade of January 2012. During each collection, temperature and humidity were measured at the soil surface and at a height of $25 \mathrm{~cm}$ and the differences (delta) in the parameters between the two measurement points were calculated.

Results: During one hour of our observation, from 0 to 42 specimens were collected, with the greatest numbers (25-40 specimens) between late November and mid- December. The activity of adult D. reticulatus (females and males in total) depended on soil and air temperature $(r=-0.6986, p<0.05)$. Soil and air humidity did not exert an impact on the questing behaviour of adult stages. In turn, the greater the moisture delta between these two measurement points was, the greater the activity of the adult tick stages was observed.

Our investigations have demonstrated differences in the questing behaviour between $D$. reticulatus females and males correlated with environmental conditions. The temperatures of soil and air increased the migratory activity in females but did not affect migration of male ticks. In turn, the deltas of temperatures $(r=-0.6986, p<0.05)$ and humidity $(r=0.6829, p<0.05)$ did not have a statistically significant effect on stimulation of female activity but they induced significant changes on the behaviour of males, for which we found a highly negative correlation between the number of active specimens and the temperature delta $(r=-0.7276, p<0.05)$ and a highly positive correlation with the humidity delta $(r=0.8199, p<0.01)$.
\end{abstract}

Conclusions: Weather changes can be accompanied by activity of adult $D$. reticulatus even in their winter diapause period. Therefore, there is an increased threat to human and animal health posed by tick-borne diseases.

Keywords: Dermacentor reticulatus, Diapause, Winter activity, Eastern Poland

\section{Background}

The meadow tick Dermacentor reticulatus (Fabricius, 1794) has a large geographical range across the temperate zone, where it usually occurs in open and midforest meadow ecosystems. It mainly infests wild and domestic animals [1-5], although specimens of this tick had been found attached to human skin [6-8]. D. reticulatus is a vector of many pathogens, e.g. Babesia canis

\footnotetext{
*Correspondence: alicja.buczek@umlub.pl

Department of Biology and Parasitology, Medical University, Radziwiłłowska

11 St., 20-080 Lublin, Poland
}

[9], Babesia microti [10], Anaplasma phagocytophilum [11], Francisella tularensis [12], spotted fever group rickettsiae $[13,14]$ and the tick-borne encephalitis virus [15]. In some areas, the species may colonize the same habitats and infest the same animal species as Ixodes ricinus (L.) [16]; unpubl. data; this may contribute to interspecific transmission of tick-borne pathogens and maintenance of natural foci of human and animal infectious diseases.

The seasonal activity of adult $D$. reticulatus has been repeatedly studied in eastern [17-19], central [20,21] and 
western [22] Europe. Although the abundance and dynamics of the activity of these ticks vary, two activity peaks have always been reported: in spring and autumn. As in the case of other exophilic tick species, the seasonal activity of $D$. reticulatus depends on environmental factors, particularly the photoperiod and temperature, and on the occurrence of tick hosts and their biological rhythms $[20,23]$.

According to the previous observations in the area of Poland, the activity of this tick species begins in mid-March at the earliest $[17,19,23]$ and ends in early December at the latest [19]. This paper presents untypical winter locomotor activities in adult $D$. reticulatus in eastern Poland.

\section{Methods}

\section{Study area}

The investigations were carried out in an area of $4,000 \mathrm{~m}^{2}$, $17 \mathrm{~km}$ away from Lublin (eastern Poland, $51^{\circ} 36^{\prime} \mathrm{N}$, $\left.22^{\circ} 58^{\prime} \mathrm{E}\right)$. The locality of $D$. reticulatus was situated on a meadow close to a large mixed forest complex dominated by pines and alders.

The study area is located in the temperate zone with a climate that is transitional between oceanic and continental. On average, the first snow cover appears in this area in the third decade of November and persists for a short period. The permanent snow cover, persisting for over 7 days appears in the second half of December. On average, it persists for 60 days. The mean temperatures of November, December, January, and February are 2.6, $-1.3,-3.5$ and $2.6^{\circ} \mathrm{C}$, respectively [24].

\section{Tick collection}

Ticks were collected between the third decade of November 2011 and the third decade of January 2012. The choice of study days depended on weather conditions. No collection of ticks was arranged after snowfall, rainfall, heavy rains, or on wet snowmelt days.

In the investigations, the flagging method was used, which involved sweeping vegetation with a $1 \mathrm{~m}^{2}$ white flannel cloth attached to a bamboo stick. After every 2-3 paces, the cloth was viewed and adult $D$. reticulatus ticks attached to it were counted (females and males separately) and released in their locality. Each collection round was carried out by one person in a $20 \times 20 \mathrm{~m}$ experimental plot and lasted for an hour. Ticks were collected during the diurnal activity peaks for this species in eastern Poland, i.e. between 1 p.m. and 2 p.m. [25].

Concurrently, during each collection round, temperature with an accuracy of $1^{\circ} \mathrm{C}$ and relative humidity with an accuracy of $1 \%$ were measured on the soil surface and at the height of $25 \mathrm{~cm}$. Based on the measurements, the temperature and humidity deltas were calculated, which is the difference between their values at the soil surface and in the air. For all the study days, the length of the photoperiod was calculated for the geographical position of the tick locality, based on the information about the sunrises and sunsets according to CET (Central European Time) (www.calendar.k-ce.pl).

\section{Statistical analysis}

The analysis of the results was performed using the STATISTICA package for Windows 9.0. The differences in the distribution of the results were analysed with the Spearman rank correlation test. Test probability at the level $\mathrm{p}<0.05$ was assumed significant, and $\mathrm{p}<0.01$ was regarded as highly significant.

\section{Results}

The present study demonstrated that adult $D$. reticulatus were active between November 11, 2011 and January 7, 2012. A total of 291 specimens, including 168 females and 123 males, were collected (Table 1). The high activity of ticks persisted from the third decade of November and mid-December. During that period, 20-42 specimens/1 hr were collected. Females dominated in the collection from early to mid-December, which was followed by a decrease in their activity, compared to the activity of males. Higher activity of males was reported between mid- and late December. At the beginning of January, only single specimens were collected, among which females were predominant.

During the study, the mean soil and air temperatures were $6.03 \pm 2.00^{\circ} \mathrm{C}$ and $6.43 \pm 1.8^{\circ} \mathrm{C}$, respectively (Table 1 ). The Spearman's test confirmed the highly significant positive correlations between the number of females and the soil surface temperature $(\mathrm{r}=0.8254, \mathrm{p}<0.01)$ and air temperature $(r=0.7724, p<0.01)$. In the case of the total number of the specimens (both females and males), there was a relatively high correlation with the soil-level temperature $(\mathrm{r}=0.6254, \mathrm{p}<0.01)$, but no correlation with the air temperature $(\mathrm{r}=-0.5115, \mathrm{p}>0.05)$ was found. No significant correlations were found between the temperature of the soil $(\mathrm{r}=0.3968, \mathrm{p}>0.05)$ and air $(r=0.2116, p>0.05)$ and the activity of males. For the temperature delta, a highly significant negative correlation with the number of males $(r=-0.7418, p<0.01)$, and a significant correlation with the activity of both genders in total $(\mathrm{r}=-0.6575, \mathrm{p}<0.05)$ was reported. In turn, the correlation between the temperature delta and the activity of females was not significant $(r=-0.5294, p>0.05)$.

Humidity measured at the ground level (76.69 \pm $9.15 \%)$ and air humidity $(68.54 \pm 7.64 \%)$ did not have a significant effect on the number of females $(r=-0.1149$, $\mathrm{p}>0.05 ; \mathrm{r}=-0.2069, \mathrm{p}>0.05)$, males $(\mathrm{r}=0.4070, \mathrm{p}>0.05$; $\mathrm{r}=0.0581, \mathrm{p}>0.05)$, and the total number of adult D. reticulatus $(\mathrm{r}=0.1659, \mathrm{p}>0.05 ; \mathrm{r}=-0.1014, \mathrm{p}>0.05)$. The humidity delta was significantly positively correlated with the number of males $(r=0.8199, p<0.01)$ and the 
Table 1 Total gender number of Dermacentor reticulatus ticks collected during particular collections in 2011 and 2012 in context of temperature and relative humidity

\begin{tabular}{lllllllllllll}
\hline Date & $\mathbf{F}$ & $\mathbf{F ~ ( \% )}$ & $\mathbf{M}$ & $\mathbf{M}(\%)$ & Total tick no. & Temp ${ }^{\circ} \mathbf{C} \mathbf{D}$ & Temp $^{\circ} \mathbf{C ~ G}$ & Temp. & RH \% D & RH \% G & RH & Day length \\
\hline 23.11 .11 & 18 & 72 & 7 & 28 & 25 & 9.2 & 9.8 & 0.6 & 55.5 & 52 & 2.5 & $8 \mathrm{~h} 33^{\prime}$ \\
$25.11 .11^{*}$ & 13 & 65 & 7 & 35 & 20 & 7.4 & 6.9 & 0.5 & 80 & 77 & 3 & $8 \mathrm{~h} 28^{\prime}$ \\
& 19 & 59.4 & 13 & 40.6 & 32 & 7.4 & 6.9 & 0.5 & 80 & 77 & 3 & $8 \mathrm{~h} 28^{\prime}$ \\
$30.11 .11^{*}$ & 13 & 50 & 13 & 50 & 26 & 5.4 & 6.1 & 0.7 & 83.5 & 70.5 & 13 & $8 \mathrm{~h} 16^{\prime}$ \\
& 20 & 58.8 & 14 & 41.2 & 34 & 5.4 & 6.1 & 0.7 & 83.5 & 70.5 & 13 & $8 \mathrm{~h} 16^{\prime}$ \\
$02.12 .11^{*}$ & 29 & 69 & 13 & 31 & 42 & 8.1 & 8.2 & 0.1 & 76.1 & 63.5 & 12.6 & $8 \mathrm{~h} 12^{\prime}$ \\
& 21 & 55.3 & 17 & 44.7 & 38 & 8.1 & 8.2 & 0.1 & 76.1 & 63.5 & 12.6 & $8 \mathrm{~h} 12^{\prime}$ \\
$16.12 .11^{*}$ & 10 & 38.5 & 16 & 61.5 & 26 & 5.2 & 5.1 & 0.1 & 82.5 & 71 & 11.9 & $7 \mathrm{~h} 54^{\prime}$ \\
& 16 & 50 & 16 & 50 & 32 & 5.2 & 5.1 & 0.1 & 82.5 & 71 & 11.9 & $7 \mathrm{~h} 54^{\prime}$ \\
$23.12 .11^{*}$ & 5 & 50 & 5 & 50 & 10 & 4.9 & 3.9 & 1 & 80.9 & 75.9 & 5 & $7 \mathrm{~h} 52^{\prime}$ \\
07.01 .12 & 4 & 66.7 & 2 & 33.3 & 6 & 2.5 & - &.- & - & - & - & $8 \mathrm{~h} 06^{\prime}$ \\
26.01 .12 & 0 & 0 & 0 & 0 & 0 & 3.6 & 4.4 & 0.8 & 63 & 62 & 1 & $8 \mathrm{~h} 26^{\prime}$ \\
\hline
\end{tabular}

F- females, M-males- no data, Temp. G- temperature measured on the soil surface, Temp. D- temperature measured at the height of $25 \mathrm{~cm}$ above the ground, $\mathrm{RH}$ - relative humidity; *- ticks were collected simultaneously by two persons at the same time (between 1 p.m. and 2 p.m.) in the separate, adjacent $20 \times 20 \mathrm{~m}$ experimental plots.

Triangle- the difference between parameter values at the soil surface and in the air (delta).

number of both females and males $(\mathrm{r}=0.6912, \mathrm{p}<0.05)$. In turn, in these investigations the activity of females $(\mathrm{r}=0.2222, \mathrm{p}>0.05)$, males $(\mathrm{r}=-0.2509, \mathrm{p}>0.05)$, and the total number of adult ticks $(r=-0.0565, \mathrm{p}>0.05)$ did not depend on the length of the day.

\section{Discussion}

Diapause is a period of arrested development and activity in ticks in conditions in which the effect of environmental factors exceeds ticks' adaptive abilities. Among the abiotic factors, the greatest effect on the seasonality of tick behaviour is exerted by the photoperiod length and temperature. Diapause is neurohormonally and hormonally stimulated and is significant in seasonal regulation of the tick developmental cycle. As indicated in our 11-year-long field research, diapause in adult $D$. reticulatus in eastern Poland begins in late November or early December [19], unpubl. data. The present investigations have shown that the high activity of these ticks can persist even throughout December, during the shortest days of the year at soil and air temperatures ca. $5^{\circ} \mathrm{C}$ (Table 1 ). It is comparable to the autumn activity peak of adult forms of the species reported in the previous studies from eastern Poland; this was $62.9 \pm 54.3$ specimens $/ 2 \mathrm{hr}$ of collection and exceeded the spring peak activity $(32.5 \pm 24.7$ specimens $/ 2 \mathrm{hr}$ of collection) [19]. We found active adult ticks in January, at air temperatures of $2.5^{\circ} \mathrm{C}$; however, they were not found at higher temperatures (soil/air temperature 3.6 and $4.4^{\circ} \mathrm{C}$, respectively), which may be explained by persistence of the snow cover in the habitat, preventing tick emergence, although, unlike in the case of an exposed surface, the snow cover and its properties (albedo, thermal conductivity) have a beneficial impact on the radiation and heat balance of the active surface [26].

This study has shown differences in the questing behaviour of $D$. reticulatus males and females caused by temperature during the winter season. The activity of females increased in parallel with rising soil and air temperature, although the difference between temperatures measured at the respective points did not exhibit a stimulating effect on these specimens. In turn, in the case of males, the bigger the temperature delta was the lowest activity they exhibited. According to Alekseev and Dubinina [26], the soil temperature gradient $1-1.5 \mathrm{~cm}$ below leaf litter and soil surface temperature seem to be the main physical parameters triggering migration of Ixodes persulcatus Schulze from the leaf litter. As many as $60 \%$ of specimens (mainly nymphs) of this tick species were active when the differences were in the range of $0-2.0 \%$.

Hubalek et al. [27] found a significant effect of the amplitude in the temperature between soil and air on the activity of $I$. ricinus nymphs and adults as well as a lack of such a correlation in Haemaphysalis concinna nymphs and adults and in D. reticulatus adults in South Moravia (Czech Republic).

As in our previous study carried out during the tick seasonal activity period in eastern Poland, we did not find dependence between the level of humidity on the soil surface and the questing behaviour of $D$. reticulatus females and males during the winter activity. However, the delta of humidity between the two measurement points had a significant impact on stimulation of the locomotor activity in males, as its increase was correlated with the 
increased numbers of active males. The results of these observations indicate presence of physiological differences between the unfed specimens in both gender groups, which determine the capacity of maintenance of favourable water balance and the dynamics of active absorption of water vapour from the atmosphere.

The differences between the reactions of $D$. reticulatus females and males to the thermal and humidity stimulus may also be related to the different degree of body chitinisation and integumental permeability to water.

In questing ticks, elevated metabolism levels and ventilation through spiracles have been reported [28]. According to Gaede and Knülle [29], at high humidity, ticks can recompense any water deficit by active absorption using a hyperosmotic secretion from the salivary glands.

The absence of a correlation between the photoperiod and the activity of adult $D$. reticulatus ticks in our investigations is caused by the small differences in the day length during the collection period. Previous observations of seasonal rhythms of activity of this species demonstrated increased numbers of active females and males during a short day. In eastern Poland, diapause in adult $D$. reticulatus began when the day length was between 9h25' and 8h53' [19].

Autumn activity of adult $D$. reticulatus stages in the population from eastern Poland is 2 to 3 times higher than spring activity $[19,30]$. During the autumn activity, the largest numbers of questing ticks were observed between the second decade of September and the end of October or mid- November. The diapause of this tick species begins, depending on the climatic conditions, between mid-November and early December and lasts until March [19].

The winter occurrence of active $D$. reticulatus ticks in this study, which had never been reported during the previous long-term field studies in eastern Poland, may be attributed to weather changes, e.g. elevated temperature, a greater number of sunny days, and shorter persistence of the snow cover [24]. The mean temperature in December 2011 was above zero $\left(1\right.$ to $\left.2^{\circ} \mathrm{C}\right)$ and differed from the mean temperatures in December $2010\left(-5\right.$ to $\left.-4^{\circ} \mathrm{C}\right)$ and $2012\left(-4\right.$ to $\left.-3^{\circ} \mathrm{C}\right)$.

According to Nosek [1] and Bogdaszewska [23], the lower thermal threshold of activity of adult $D$. reticulatus ticks is $1^{\circ} \mathrm{C}$. Hubalek et al. [27] reported questing of the tick species at air/soil temperatures of $0.7 /-0.1^{\circ} \mathrm{C}$. Based on investigations of Dermacentor variabilis, other authors have emphasized that, although it starts at the temperature rise, seasonal activity is not directly related to the daily temperature, but rather to increasing solar radiation [31]. As shown by our research, the response of $D$. reticulatus to a particular photoperiod is modified not only by temperature, but also by other conditions prevailing in the microhabitat, e.g. the snow cover. At lower temperatures, which limit the absorption of atmospheric water, ticks enter diapause earlier [19]. The ambient temperature plays a role in initiation and length of diapause by changing the dynamics of tick metabolism. Diapause length depends on the quantity of nutrient reserves accumulated during the consecutive tick developmental stages [32].

Similar to our study, high activity of nymphs and adult forms of another exophilic species (the European tick $I$. ricinus) was reported near Berlin (Germany). This was observed at minimum temperatures in January and February of 0.6 and $2.3^{\circ} \mathrm{C}$, respectively, and mean temperature of ca. $7^{\circ} \mathrm{C}$, i.e. in the typical period of its diapause in the temperate zone [33]. It is suggested that global warming and weather conditions can contribute to expansion of tick ranges and to changes in the dynamics of their activity and seasonal patterns of tick-borne diseases [30,34-43].

\section{Conclusions}

The occurrence of active $D$. reticulatus ticks during the winter months in the temperate zone implies a potentially high risk of animal infestations and transmission of tick-borne diseases during weather changes during this period.

Among abiotic factors, soil and air temperature probably play the most important role in activation of $D$. reticulatus females, which have the greatest epidemiological importance due to their wide host range and feeding physiology.

The differences in the reaction of $D$. reticulatus females and males to temperature and humidity changes may be associated with the different structure of their integument and differences in physiological traits between specimens of the two genders determining maintenance of favourable water balance.

\section{Competing interests}

The authors declare that they have no competing interests.

\section{Authors' contributions}

$A B$ designed the study, contributed to analysis and interpretation of obtained data, drafted the initial form of the manuscript, and reviewed comments by co-authors; KB contributed to interpretation of the data and to the statistical design and analysis plan and participated in writing of the manuscript. ZZ conducted statistical analyses and contributed to acquisition of data. All authors read and approved the final manuscript.

Received: 22 January 2014 Accepted: 20 May 2014

Published: 28 May 2014

\section{References}

1. Nosek J: The ecology and public health importance of Dermacentor marginatus and D. reticulatus ticks in central Europe. Folia Parasitol 1972, 19:93-102.

2. Szymański S: Distribution of the tick Dermacentor reticulatus (Fabricius, 1794) (Ixodidae) in Poland. Acta Parasitol Pol 1986, 31:143-154.

3. Kadulski S: Ectoparasites of Polish arthrodactylous game animals. Acta Parasitol Pol 1975, 23:493-535.

4. Chaerebout E, Losson B, Cochez C, Casaert S, Dalemans AD, De Cat A, Madder M, Segerman C, Heyman P, Lempereur L: Ticks and associated 
pathogens collected from dogs and cats in Belgium. Parasit Vectors 2013 6:183

5. Duscher GG, Feiler A, Leschnik M, Joachim A: Seasonal and spartal distribution of ixodid tick species feeding on naturally infested dogs from Eastern Austria and the influence of acaricides/repellents on these parameters. Parasit Vectors 2013, 6:76

6. Fernandez-Soto P, Perez-Sanchez R, Encinas-Grandes A, Alamo Sanz R: Rickettsia slovaca in Dermacentor ticks found on humans in Spain. Eur J Clin Microbiol Infect Dis 2006, 25:129-131.

7. Bartosik K, Sitarz M, Szymańska J, Buczek A: Tick bites on humans in the agricultural and recreational areas in south-eastern Poland. Ann Agric Environ Med 2011, 18:151-157.

8. Bursali A, Keskin A, Tekin S: Ticks (Acari: Ixodida) infesting humans in the provinces of Kelkit Valley, a Crimean-Congo Hemorrhagic Fever endemic region in Turkey. Exp Appl Acarol 2013, 59:507-515.

9. Martinod S, Brossard M, Moreau Y: Immunity of dogs against Babesia canis, its vector tick Dermacentor reticulatus, and Ixodes ricinus in endemic area. J Parasitol 1985, 71:269-273.

10. Wójcik-Fatla A, Bartosik K, Buczek A, Dutkiewicz J: Babesia microti in adult Dermacentor reticulatus ticks from eastern Poland. Vector Borne Zoonotic Dis 2012, 12:841-843.

11. Wirtgen M, Nahayo A, Linden A, Losson B, Garigliany M, Desmecht D: Detection of Anaplasma phagocytophilum in Dermacentor reticulatus ticks. Vet Rec 2011, 168:195.

12. Hubálek Z, Sixl W, Halouzka J: Francisella tularensis in Dermacentor reticulatus ticks from the Czech Republic and Austria. Wien Klin Wochenschr 1998, 110:909-910.

13. Dobec M, Golubic D, Punda-Polic V, Kaeppeli F, Sievers M: Rickettsia helvetica in Dermacentor reticulatus ticks. Emerg Infect Dis 2009, 15:98-100.

14. Tijsse-Klasen E, Hansford KH, Jahfari S, Phipps P, Sprong H, Medlock JM: Spotted fever group rickettsiae in Dermacentor reticulatus and Haemaphysalis punctata ticks in the UK. Parasit Vectors 2013, 6:212.

15. Wójcik-Fatla A, Cisak E, Zając V, Zwoliński J, Dutkiewicz J: Prevalence of tick-borne encephalitis virus in Ixodes ricinus and Dermacentor reticulatus ticks collected from the Lublin region (eastern Poland). Ticks Tick Borne Dis 2011, 2:16-19.

16. Welc-Falęciak R, Bajer A, Behnke JM, Siński E: Effects of host diversity and the community composition of ixodid ticks (Ixodidae) on Babesia microti infection. Int J Med Microbiol 2008, 298(Suppl 1):235-242.

17. Szymański S: Seasonal activity of Dermacentor reticulatus (Fabricius, 1794) (Acarina, Ixodidae) in Poland. I Adults Acta Parasitol Pol 1987, 31:247-255.

18. Razumova IV: The activity of Dermacentor reticulatus Fabr. (Ixodidae) ticks in nature. Med Parazitol (Mosk) 1998, 4:8-14. in Russian.

19. Bartosik K, Wiśniowski L, Buczek A: Abundance and seasonal activity of adult Dermacentor reticulatus (Acari: Amblyommidae) in eastern Poland in relation to meteorological conditions and the photoperiod. Ann Agric Environ Med 2011, 18:340-344.

20. Daniel M, Szymański S, Cerný V, Dusbábek F, Honzákowá E, Olejniĉek J: A comparison of developmental dynamics of Dermacentor reticulatus (Fabr.) of different geographic origins and their affection by different microclimate. Folia Parasitol (Praha) 1980, 27:63-69.

21. Széll Z, Sréter-Lancz Z, Márialigeti K, Sréter T: Temporal distribution of Ixodes ricinus, Dermacentor reticulatus and Haemaphysalis concinna in Hungary. Vet Parasitol 2006, 141:377-379.

22. Martinod S, Gilot B: Epidemiology of canine babesiosis in relation to the activity of Dermacentor reticulatus in southern Jura (France). Exp Appl Acarol 1991, 11:215-222.

23. Bogdaszewska Z: Range and ecology of Dermacentor reticulatus (Fabricius, 1794) in Mazuria focus. III. The influence of temperature and day length on the activity of hungry adult ticks in laboratory conditions. Wiad Parazytol 2004, 50:739-745 (in Polish).

24. Kaszewski BM: Climatic Conditions in Lublin Region. Lublin: Academic Press UMCS; 2008 (in Polish).

25. Bartosik K, Wiśniowski Ł, Buczek A: Questing behavior of Dermacentor reticulatus adults (Acari: Amblyommidae) during diurnal activity periods in eastern Poland. J Med Entomol 2012, 49:859-864.

26. Alekseev AN, Dubinina HV: Abiotic parameter and diel and seasonal activity of Borrelia-infected and uninfected Ixodes persulcatus (Acari: Ixodidae). J Med Entomol 2000, 37:9-15.

27. Hubálek Z, Halouzka J, Jucicová Z: Host-seeking activity of ixodid ticks in relation to weather variables. J Vector Ecol 2003, 28:159-165
28. Lighton J, Fielden L, Rechav Y: Discontinuous ventilation in a non-insect, the tick Amblyomma marmoreum (Acari, Ixodidae): characterization and metabolic modulation. J Exp Biol 1993, 180:229-245

29. Gaede K, Knülle W: On the mechanism of water vapour sorption from unsaturated atmospheres by ticks. J Exp Biol 1997, 200:1491-1498.

30. Buczek A, Bartosik KA, Wiśniowski $Ł$, Tomasiewicz K: Changes in population abundance of adult Dermacentor reticulatus (Acari: Amblyommidae) in long-term investigations in eastern Poland. Ann Agric Environ Med 2013, 20:269-272

31. Atwood EL, Sonenshine DE: Activity of American dog tick, Dermacentor variabilis (Acarina: Ixodidae), in relation to solar energy changes. Ann Entomol Soc Am 1967, 60:354-362.

32. McEnroe WD: Stability of Dermacentor variabilis populations (Acari: Ixodidae). Folia Parasitol 1990, 37:340-342.

33. Dautel H, Dippel C, Kämmer D, Werkhausen A, Kahl O: Winter activity of Ixodes ricinus in a Berlin forest. Int J Med Microbiol 2008 , 298(Suppl 1):50-54.

34. Zeman P, Bene C: A tick-borne encephalitis ceiling in Central Europe has moved upwards during the last 30 years: possible impact of global warming? Int J Med Microbiol 2004, 293(Suppl 37):48.

35. Parola P, Socolovschi C, Jeanjean L, Bitam I, Fournier PE, Sotto A, Labauge $P$, Raoult D: Warmer weather linked to tick attack and emergence of severe rickettsioses. PLoS Negl Trop Dis 2008, 2:e338.

36. Scharlemann JP, Johnson PJ, Smith AA, Macdonald DW, Randolph SE: Trends in ixodid tick abundance and distribution in Great Britain. Med Vet Entomol 2008, 22:238-247.

37. Gray JS, Dautel H, Estrada-Peña A, Kahl O, Lindgren E: Effects of climate change on ticks and tick-borne diseases in Europe. Interdiscip Perspect Infect Dis 2009:593232. doi: 10.1155/2009/593232.

38. Bullová E, Lukán M, Stanko M, Petko B: Spatial distribution of Dermacentor reticulatus tick in Slovakia in the beginning of the 21 st century. Vet Parasitol 2009, 165:357-360.

39. Gilbert L: Altitudinal patterns of tick and host abundance: a potential role for climate change in regulating tick-borne diseases? Oecologia 2010, 162:217-225.

40. Randolph SE: To what extent has climate change contributed to the recent epidemiology of tick-borne diseases? Vet Parasitol 2010, 167:92-94.

41. Dobson AD, Taylor JL, Randolph SE: Tick (Ixodes ricinus) abundance and seasonality at recreational sites in the UK: hazards in relation to fine-scale habitat types revealed by complementary sampling methods. Ticks Tick Borne Dis 2011, 2:67-74.

42. Jaenson TGT, Jaenson DGE, Petersson E, Lindgren E: Changes in the geographical distribution and abundance of the tick Ixodes ricinus during the past 30 years in Sweden. Parasit Vectors 2012, 5:8.

43. Medlock JM, Hansford KM, Bormane A, Derdakova M, Estrada-Peña A, George JC, Golovljova I, Jaenson TG, Jensen JK, Jensen PM, Kazimirova M, Oteo JA, Papa A, Pfister K, Plantard O, Randolph SE, Rizzoli A, Santos-Silva MM, Sprong $H$, Vial L, Hendrickx G, Zeller $H$, Van Bortel W: Driving forces for changes in geographical distribution of Ixodes ricinus ticks in Europe. Parasit Vectors 2013, 6:1-11

doi:10.1186/1756-3305-7-245

Cite this article as: Buczek et al:: Changes in the activity of adult stages of Dermacentor reticulatus (Ixodida: Amblyommidae) induced by weather factors in eastern Poland. Parasites \& Vectors 2014 7:245.

\section{Submit your next manuscript to BioMed Central and take full advantage of:}

- Convenient online submission

- Thorough peer review

- No space constraints or color figure charges

- Immediate publication on acceptance

- Inclusion in PubMed, CAS, Scopus and Google Scholar

- Research which is freely available for redistribution 